\title{
UNDERSTANDING RESEARCH METHODS FOR SOCIAL EPIDEMIOLOGY: A NARRATIVE REVIEW
}

\author{
Afrona Elisabeth Lelan Takaeb
}

Public Health Faculty, Nusa Cendana University, located in Kupang NTT

Corresponding Author : Afrona Elisabeth Lelan Takaeb

Email : afrona.takaeb@staf.undana.ac.id

\begin{abstract}
Background: Students or health workforces who are interested in understanding social epidemiology are required to have an adequate competency of research. This paper aimed to describe about the difference between quantitative and qualitative methodological approach in social epidemiology and types epidemiological study.

Methods: Method applied was a narrative review to 28 English Text books, 2 Grey Literatures and 3 supported articles as example. All of these literatures have been reviewed based on key concept according to the purpose of this paper.

Results: The basic premise or paradigm underpinning quantitative and qualitative methodology is related to their ontology and epistemology. Quantitative research or "the science of number" is based on the ontology of "objectivism" and the epistemology of "positivist or realist or functional or naturalism or logical empiricism while Qualitative research or "the word science" is based on the ontology of "constructivism" and the epistemology of "interpretivism. Study in epidemiology is divided into two parts that are, observational studies and experimental studies. Types of observational studies are descriptive study and analytic such as cross sectional, case control study and cohort while its counterparts are randomized control trials (RCT), field trials, and community trials.

Conclusion: Quantitative and Qualitative approach in research in social epidemiology is classified based on their ontology and epistemology. There are two studies in epidemiology, namely, observational study (descriptive and analysis) and experimental study.
\end{abstract}

Keywords: Social, Epidemiology, Quantitative, Qualitative, Observational, Experimental. 


\section{INTRODUCTION}

Social epidemiology is the branch of epidemiology that studies the social distribution and social determinant of states of health' (1). Students or health workforces who are interested in understanding social epidemiology are required to have an adequate competency of research $(2,3)$. The question which arise here are, what are the methodological approaches in research? What are the types of epidemiological study? This paper aims to describe and discuss the quantitative and qualitative approaches and types of epidemiological study. This paper will be divided into two sections, which are understanding the qualitative and quantitative approaches, and Comparison between observational epidemiology and experimental studies.

\section{METHOD}

Method applied in this paper was a narrative review to find relevance literature about research in social epidemiology. This paper was obtained from reviewing 28 English text books, 2 grey literatures and 3 supported articles as example. They were examined in detail based on their relevancy to the topic and as a narrative review it was analyzed descriptively based on the key concept and the author's expertise in relation to public health and social epidemiology.

\section{RESULTS}

There are two themes emerged in this the review, namely:

1. Understanding quantitative and qualitative approaches. This theme aimed to distinguish quantitative and quantitative approach based on their paradigm and their usage in research of social epidemiology.

2. Comparison between observational epidemiology and experimental studies. The purpose of this theme was to explore two main kinds of research in epidemiology and their example.

\section{DISCUSSION}

\section{Understanding quantitative and qualitative approaches.}

\section{a. The difference between a quantitative and qualitative approach}

The basic premise or paradigm underpinning quantitative and qualitative methodology is related to their ontology or "what is out there to know about and epistemology or "what and how can we know about it" (4). Quantitative research or 'the science of number" is based on the ontology of "objectivism" and the epistemology of "positivist or realist or functional or naturalism or logical empiricism" which is based on the belief that the reality or truth already exists and the researcher is charged to 'observe, measure, predict or to find out or to prove' the reality $(4,5,6,7)$.For example, to know whether a person is healthy or not a quantitative scholar will use some tangible criteria such as the existence of diseases and impairment as their theory, to measure whether this person is healthy or not.

Qualitative research or "the word science" is based on the ontology of "constructivism" and the epistemology of "interpretivism" which believes the truth or reality is not already existing but depends on the idea that reality is "socially constructed" through communication and interaction and practice, causing people to have their own meaning or understanding about a particular phenomenon or issue $(4,5,6,7)$. This approach emphasizes more that the researchers is charged with the task to understand people perspective's called 'verstehen' and to immerse themselves into the natural setting by interacting directly with subject, a process called 'thick description' (6). Taking the previous example, to know whether a person is healthy or not, a qualitative researcher will find the answer by understanding how that person defines the concept of health, which probably depends on his experience or 
culture such as 'he is healthy if he can eat rice three times a day'.

Based on their ontology and epistemology, a quantitative researcher uses the theory deductively, which means that the researcher is charged with testing or verifying or confirming the theory that has already existed (Broom 3,5,7). This is very beneficial in finding diversity or variance in the extent of a problem or health issue among a population (3). The procedure to get the findings has to be set up rigorously or structured as an attempt to reduce bias in order to have valid and reliable findings such as probability sampling and defining variables and statistical analysis tools and these are considered mainly as its strength $(3,5)$.The researches review the literature that already exists carefully as the purpose is to test the theory, set up the objective specifically, assign variables and define them operationally and establish an instrument to measure or observe that variables $(3,9)$. Because the common question in quantitative research is related to numeric facts such as how often or how many, so the implication of this in data collection and data analysis or the findings is that they will be displayed or transformed into numbers or statistics $(3,6,9)$.

Surveys with questionnaire and structured interview with an interview schedule are the usual method and instrument in quantitative study $(3,10,11)$. A survey is a descriptive study which provides a general picture of the population by conducting study in a chosen subject or sample while questionnaires consist of written questions which need to be answered by a respondent (12). In a structured interview, the researcher has arranged some questions specifically in an interview schedule and uses that as his guideline in the interview (3).

Alternatively, a qualitative research uses the theory inductively which means that the researcher is charged with theory development and interact directly with the participant $(5,7,8)$. Unlike quantitative approach, it features flexibility and fluidity in its approach or it has unstructured approach such as using non probability sampling and small subjects because it aims to develop an understanding and interpretation of people experience's in a particular issue $(3,5,13)$. This is the strength of this approach which cannot be obtained by its counterpart (24).As a qualitative study does not aim to test the theory, the purpose of a literature review is to provide acceptable reasons why a research problem is necessary to study (9).The aim of the study is designed generally or broadly, as well as the questions asked in an attempt to make the respondent being more generative in responding to the question (9). A common question which is asked is related to explanation such as why and how, the data includes people's feelings, and their expression of belief or perception is collected in word or image so that the data analysis will be displayed descriptively or narratively which impacts on developing description and themes in data analysis called content analysis $(3,5,14)$. Then, the terms rigour and trustworthiness are the terms used in qualitative study for legitimising the findings as (13).

Focus Group Discussion, in depth interview and observation are common methods applied in qualitative research (3). FGD is a method whereby 6-12 participants are brought together to have discussion on a particular issue led by the researcher and it is very useful to have people's experiences or view point or new information through the dynamic or the interaction which exists in that discussion $(11,15,16)$. In depth interviews or unstructured interview applies 'a grand tour' question whereby the participant is not given direct questions in order to have a lot of information from the subject $(17,18)$. The question 'in your view what is health?' is a better question to be asked than the question 'Does being physically healthy mean health for you?'.A type of observation is participant observation, a method by which a researcher collects data by spending time, probably 
between six months and two years to interact or observe the subject directly $(11,19,20)$.

\section{b. Quantitative and qualitative approach in Social epidemiology}

Social epidemiology which is 'the branch of epidemiology that studies the social distribution and social determinant of states of health' (1) is commonly featured by measurement such as incidence and prevalence (21) with the result that social epidemiology seems dominated by the quantitative approach and is less concerned with qualitative research. However, in public health, understanding the causes of a health issue is not solely related to a medical perspective but is also related to social determinants of health, which are, 'factors in which people live and work",(22) or 'causes of the causes' (23). Additionally, the concept 'determinant' in the definition of epidemiology is related to all aspect in human life including social and cultural factors (21) which according to Padgett (2012) is crucial to understand in the new public health (5). Moreover, the interaction of human behaviour with health issue is very complex but can be obtained through the strength of the qualitative approach (24). Therefore, superiority of these two approaches has to be erased (3) as they have their own contribution in building up knowledge particularly in social epidemiology.

Based on the explanation above, it is suggested that the researcher does not put themselves in favour of just one approach but combines the strength of these two approaches to apply suitable methods from these two approaches in finding the research question, which is called mixed method or Q2 or Q Squared $(3,25)$. Mixed methods are the underpinning of pragmatism paradigm which accommodates the philosophy of both quantitative and qualitative approaches, leading to the need to applied method of qualitative and quantitative approach to have more significant findings $(3,5,25)$. It is important to remember that a research is led by a research question and the researcher by applying mixed methods prevent themselves of standing on the fence about whether to use a qualitative or quantitative approach but rather they choose the best methods from these two approaches to have a qualified result or to have a result which cannot be achieved solely by one approach $(3,4,26)$. As such it will be called mixed method if a research applies a survey and questionnaire as their quantitative methods with focus group discussion or in-depth interview as their qualitative methods. Using two methods from one approach such as focus group discussion and in depth interview is not a mixed method $(3,5)$. Mixed methods bring advantages in producing a best outcome or finding, but it is challenging as it needs more resources to be involved such as time, expert and participant, and skills, and there is probability of dominance of one approach (25). Tritter (2007) points out it is an important aspect to consider in the mixed methods which is to integrate the data from the different methods properly in analysis and the researcher should have a prediction in advance about how the result and the final paper will be presented (27).

\section{Comparison between observational epidemiology and experimental studies}

Study in epidemiology is divided into two parts that are, observational studies and experimental studies. They are divided based on the existence of intervention in the studies, whereby observational studies are conducted without intervention from the researcher while experimental studies involve intervention from the researcher in controlling the variables $(8,21)$.A Researcher in an experimental study, measure the change in a variable whereby the change is brought intentionally (28). Types of observational studies are descriptive study (only provides description of the health status of population such as mortality or 
morbidity) such as cross sectional or a survey conducted in national setting such as Indonesia Demography Health Survey (IDHS), and analytic study (observe the relationship between cause and outcome) such as cross sectional, case control study and cohort while its counterparts are randomized control trials (RCT), field trials, and community trials $(3,21,23)$. This paper highlights some of these types of study which are cross sectional study, case control study and RCT.

Cross sectional study or prevalence study or one shot or status study is a common, simpler and inexpensive epidemiological study which aims to find a general picture of a health issue in a particular population whereby risk factor and effect is observed simultaneously $(3,21)$. For example, in their cross sectional study, Akinleye et al 2009 (30) observed the knowledge (risk factor) and Intermittent preventive treatment for prevention of malaria in pregnancy or IPTp (effect) in one period of time among pregnant women in Nigeria and captured the picture that $52.2 \%$ of the respondents had heard about IPTp but only $23 . \%$ were able to define it. So, knowledge and IPTp was observed at one point of time.

Case control which is used to calculate an odds ratio (OR), determines the risk factor of an outcome or a disease through conducting study retrospectively among two groups, one group as the case group is people with a particular diseases or health issue, and people without these diseases or health issue are in another group called the control group (Bonita 21,29). For example, in their case- control study, EvjenOlsen et al 2008(31) chose two groups, 45 cases of maternal mortality in 1995 and 1996 as the case group and 135 antenatal attendees in similar population, geographical area and time span 1995 and 1996 as the control group. They found that risk of maternal death in women aged from 35-49 years was 4 times more likely than women ages $15-24$ years (OR 4.0; 95\%CI 1.5-10.6) and women who husband adhered to traditional belief were 2.6 times more likely to have risk a of maternal death (OR 2.6; 95\% CI 1.2-5.7).

RCT aims to find intervention efficacy whereby participants who are selected randomly are divided into a group with intervention or the study group and a group without intervention or the control group $(21,32)$. For example, by using RCT, Mullany et al 2007 (33), assessed the impact of including husbands in antenatal health education services on maternal practices in urban Nepal by selecting the eligible participant randomly and dividing them into three groups, women who received education with their husband, women who received education alone and women who received no education In this trial, the author gave intervention to the participant who was woman who received education accompanied by her husband. The finding indicated that women who received education with husbands (study group) were more likely to attend a postpartum visit than women who received education alone (control group) [RR $51.25,95 \%$ CI 5 (1.01, 1.54)] or no education (control group) [RR $51.29,95 \%$ CI $5(1.04,1.60)]$. Based on this, the authors strongly argue the importance of husband involvement in maternal education as it significant has impact on maternal health

\section{CONCLUSION}

Quantitative and Qualitative approach in research in social epidemiology is classified based on their ontology and epistemology. There are two studies in epidemiology, namely, observational study (descriptive and analysis) and experimental study.

Indonesian Journal Of Health Sciences Research and Development 


\section{REFERENCES}

1. Berkman, LF \&Kawachi, I 2000, 'A historical framework for social epidemiology', in Berkman, LF \&Kawachi, I, Social Epidemiology, Oxford University Press, New York, pp. 3-12

2. Joss, N \&Keleher, H 2011, 'Competencies and careers in Public Health and Health Promotion', in Keleher \& MacDougall (ed.), Understanding Health, 3rd edn, Oxford University Press, Melbourne, pp. 299310

3. Kumar, R 2014, Research methodology: a step-by-step guide for beginners, 4thedn, Sage Publication

4. Grix, J 2002,'Introducing students to the generic terminology of social research', Politics, vol.22, no. 3, pp. 175-186.

5. Liamputtong, P 2013, 'The science of words and the science of numbers; Research methods as foundation for evidence based practice in health', in Liamputtong, P (ed.), Research Methods in Health, 2nd edn, Oxford University Press, Australia \& New Zealand, pp. 3-23

6. Tracy,S 2013, Qualitative research methods, Wiley-Blackwell, UK

7. Broom, A \& Wills, E 2007, 'Competing paradigms and Health Research', in Saks, M. \&Allsop, J,Researching Health: Qualitative, Quantitative and Mixed Methods, 1st edn, Sage Publications, pp. 16-31

8. Creswell, JW 2009, Research Design, Qualitative, Quantitative and Mixed Approaches, 2ndedn, Sage Publication.

9. Creswell, JW 2003, Educational Research, Planning, conducting, and evaluating Qualitative, Quantitative reserarch, 2ndedn, Pearson Merrill Prentice Hall.

10. Calnan, M 2007,'Quantitative survey methods in health research', in Saks,
M. \&Allsop, J,Researching Health: Qualitative, Quantitative and Mixed Methods, 1st edn, Sage Publications, pp. 174-196

11. Issel, ML 2009, Health Program Planning and Evaluation: A Practical Systematic Approach for Community health, 3rdedn, Jones and Bartlett Learning, Burlington MA.

12. Schofield, MJ \& Forrester - Knauss, C 2013, 'Survey and questionnaires in health research', in Liamputtong, $\mathrm{P}$ (ed.), Research Methods in Health, 2nd edn, Oxford University Press, Australia \& New Zealand, pp. 198-218

13. Liamputtong, P 2009, Qualitative Research Methods, 3rdedn, Oxford University Press, Australia \& New Zealand.

14. Alaszewski, A 2007, 'Using document in health research', in Saks, M. \&Allsop, J, Researching Health: Qualitative, Quantitative and Mixed Methods, 1st edn, Sage Publications, pp. $57-75$

15. Green, J 2007, 'The use of focus group discussion in research into health', in Saks, M. \&Allsop, J, Researching Health: Qualitative, Quantitative and Mixed Methods, 1st edn, Sage Publications, pp. 112-132

16. Davidson, P, Halcomb, EJ \&Gholizadeh, L 2013, 'Focus Group in health research', in Liamputtong, $\mathrm{P}$ (ed.), Research Methods in Health, 2nd edn, Oxford University Press, Australia $\&$ New Zealand, pp. 54-71

17. Low, J 2007, 'Unstructured interview and health research', in Saks, M. \&Allsop, J, Researching Health: Qualitative, Quantitative and Mixed Methods, 1st edn, Sage Publications, pp. 75-91

18. Serry, T \&Liamputtong, P 2013, 'The in-depth interviewing method in health', in Liamputtong, $\mathrm{P}$ (ed.), Research Methods in Health, 2nd edn, Oxford University Press, Australia \& New Zealand, pp. 39-53 
19. Hughes, D 2007, 'Participant observation in health research', in Saks, M. \&Allsop, J, Researching Health: Qualitative, Quantitative and Mixed Methods, 1st edn, Sage Publications, pp. 92-111

20. Furlong, M 2013, 'Clear at a distance, Jumbled up close' ; Observation, Immersion, and Reflection in the process that is creative research', in Liamputtong, P (ed.), Research Methods in Health, 2nd edn, Oxford University Press, Australia \& New Zealand, pp. 144-158

21. Bonita, R, Beaglehole, R \&Kjellstrom, $\mathrm{T}$ 2006, Basic epidemiology 2nd edition, WHO, Geneva

22. World Health Organization 2010, Action on the social determinants of health : Learning from previous experiences, Geneva

23. Commission on Social Determinant of Health 2008, Closing the gap in a generation: health equity through action on the social determinants of health, Geneva

24. Baum, F 2008, The New Public Health, 3rd edn, Oxford University Press, Melbourne

25. Gribich, C 2013, 'Integrated methods in health research', in Liamputtong, $\mathrm{P}$ (ed.), Research Methods in Health, 2nd edn, Oxford University Press, Australia \& New Zealand, pp. 311-322

26. Taket, A 2013, 'The use of mixed methods in health research', in Liamputtong, P (ed.), Research Methods in Health, 2nd edn, Oxford University Press, Australia \& New Zealand, pp. 323-343

27. Tritter, J 2007, 'Mixed Methods and Multidisciplinary research in health care', in Saks, M. \&Allsop, J,Researching Health: Qualitative,
Quantitative and Mixed Methods, 1st edn, Sage Publications, pp. 301-318

28. Siriwardena, AN 2007, 'Experimental Methods in Health research', in Saks, M. \&Allsop, J,Researching Health: Qualitative, Quantitative and Mixed Methods, 1st edn, Sage Publications, pp. 246-264

29. Graham, M 2013, 'How do we know what we know in health research', in Liamputtong, P (ed.), Research Methods in Health, 2nd edn, Oxford University Press, Australia \& New Zealand, pp. 219-233

30. Akinleye, SO, Falade, CO \&Ajayi, IO 2009, 'Knowledge and utilization of intermittent preventive treatment for malaria among pregnant women attending antenatal clinics in primary health care centers in rural southwest, Nigeria: a cross-sectional study', BMC Pregnancy Childbirth, vol. 9, p. 28.

31. Evjen-Olsen, B, Hinderaker, SG, Lie, RT, Bergsjo, P, Gasheka, P \&Kvale, G 2008, 'Risk factors for maternal death in the highlands of rural northern Tanzania: a case-control study', BMC Public Health, vol. 8, p. 52.

32. Landorf, KB 2013, 'Clinical Trials ; the good, the bad and the ugly', in Liamputtong, P (ed.), Research Methods in Health, 2nd edn, Oxford University Press, Australia \& New Zealand, pp. 234-248

33. Mullany, BC, Becker, S \&Hindin, MJ 2007, 'The impact of including husbands in antenatal health education services on maternal health practices in urban Nepal: results from a randomized controlled trial', Health Educ Res, vol. 22, no. 2, pp. 166-76. 